\title{
A rare variety of congenital adrenal hyperplasia with mosaic Klinefelter syndrome: a unique combination presenting with ambiguous genitalia and sexual precocity
}

\author{
M A Shehab', Tahseen Mahmood', M A Hasanat1, Md Fariduddin', Nazmul Ahsan², \\ Mohammad Shahnoor Hossain², Md Shahdat Hossain² and Sharmin Jahan'
}

1Department of Endocrinology, BSMMU, Dhaka, Bangladesh and 2Department of Genetic Engineering \& Biotechnology, University of Dhaka, Dhaka, Bangladesh

\author{
Correspondence \\ should be addressed \\ to S Jahan \\ Email \\ sharmindmc@yahoo.com
}

\section{Summary}

Congenital adrenal hyperplasia (CAH) due to the three-beta-hydroxysteroid-dehydrogenase (3 $\beta$-HSD) enzyme deficiency is a rare autosomal recessive disorder presenting with sexual precocity in a phenotypic male. Klinefelter syndrome (KS) is the most common sex chromosome aneuploidy presenting with hypergonadotropic hypogonadism in a male. However, only a handful of cases of mosaic KS have been described in the literature. The co-existence of mosaic KS with CAH due to 3 $\beta$-HSD enzyme deficiency portrays a unique diagnostic paradox where features of gonadal androgen deficiency are masked by simultaneous adrenal androgen excess. Here, we report a 7-year-old phenotypic male boy who, at birth presented with ambiguous genitalia, probably a microphallus with penoscrotal hypospadias. Later on, he developed accelerated growth with advanced bone age, premature pubarche, phallic enlargement and hyperpigmentation. Biochemically, the patient was proven to have CAH due to 3 $\beta$-HSD deficiency. However, the co-existence of bilateral cryptorchidism made us to consider the possibility of hypogonadism as well, and it was further explained by concurrent existence of mosaic KS $(47, X X Y / 46, X X)$. He was started on glucocorticoid and mineralocorticoid replacement and underwent right-sided orchidopexy on a later date. He showed significant clinical and biochemical improvement on subsequent follow-up. However, the declining value of serum testosterone was accompanied by rising level of FSH thereby unmasking hypergonadotropic hypogonadism due to mosaic KS. In future, we are planning to place him on androgen replacement as well.

\section{Learning points:}

- Ambiguous genitalia with subsequent development of sexual precocity in a phenotypic male points towards some unusual varieties of $\mathrm{CAH}$.

- High level of serum testosterone, adrenal androgen, plasma ACTH and low basal cortisol are proof of CAH, whereas elevated level of 17-OH pregnenolone is biochemical marker of 3 $\beta$-HSD enzyme deficiency.

- Final diagnosis can be obtained with sequencing of HSD3B2 gene showing various mutations.

- Presence of bilateral cryptorchidism in such a patient may be due to underlying hypogonadism.

- Karyotyping in such patient may rarely show mosaic $K S(47, X X Y / 46, X X)$ and there might be unmasking of hypergonadotropic hypogonadism resulting from adrenal androgen suppression from glucocorticoid treatment. 


\section{Background}

The term congenital adrenal hyperplasia (CAH) encompasses a group of autosomal recessive disorders, each of which involves a deficiency of enzyme involved in the biosynthetic pathway of glucocorticoids, with or without involvement of mineralocorticoids (1). CAH due to the $3 \beta$-HSD enzyme deficiency is a rare autosomal recessive disorder that results from mutations within $H S D 3 B 2$ gene encoding $3 \beta$-HSD type 2 enzyme. It is an extremely rare form of CAH with only a number of cases till its first description in 1962 (2). It affects both sexes with a heterogeneous clinical presentation ranging from the severe salt-wasting crisis to the non-salt-wasting form, with or without ambiguous genitalia and/or premature pubarche in young children and hirsutism with menstrual disorders in older females. On the other hand, Klinefelter's syndrome (KS) is the most common form of chromosomal aneuploidy, occurring in about $0.1-0.2 \%$ of the male population (3). It was first described in 1942 (4) as a syndrome characterized by gynecomastia, small and firm testes, azoospermia and elevated levels of serum follicle-stimulating hormone (FSH). The majority of KS patients have the 47,XXY karyotype. Mosaicism like 47,XXY/46,XX with clinical features suggestive of KS is very rare. Thus far, only about 10 cases have been described in literature (5). Herein, we describe the first genotype proven case from Bangladesh, affected by both CAH due to $3 \beta$-HSD deficiency and mosaic $\mathrm{KS}(47, \mathrm{XXY} / 46, \mathrm{XX})$; the first causing androgen excess, and the latter androgen deficiency and thus displaying a distinctive pattern of amalgamation, defying the popular notion of Occam's razor.

\section{Case presentation}

A 7-year-old child was referred to us from the department of urology for the medical evaluation of penoscrotal hypospadius with bilateral cryptorchidism since birth. The child was the first issue of a consanguineous marriage (Fig. 1) born by normal delivery at a remote local hospital. The antenatal and peripartum history were uneventful except for the baby's ambiguous genitalia that created confusion on gender assignment, but was eventually declared as a male on clinical basis without further evaluation or karyotyping. The child (Fig. 2) was brought up as a male with normal developmental milestones and satisfactory school performance. However, since 7 years of age, he was noticed to have accelerated growth with appearance of axillary and pubic hair with progressive blackening of skin. His parents also noticed rapid phallic

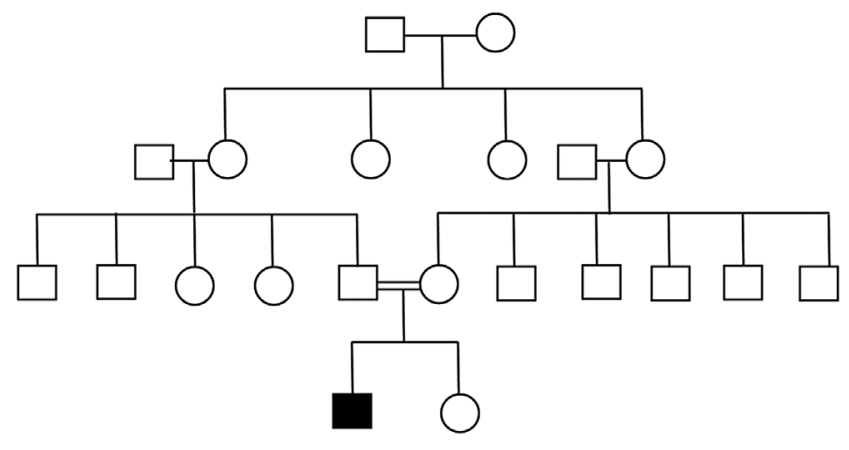

Figure 1

Pedigree chart of the subject.

enlargement that brought him to medical attention. He had occasional nausea and diarrhea, however, denied to have any weakness, fatigue or postural dizziness. There was no history of salt wasting crisis, hypertension, maternal virilization during antenatal period, intake of related drugs or family history of similar type of illness or neonatal death. On examination, his height was just above 95th percentile, BMI $12.71 \mathrm{~kg} / \mathrm{m}^{2}$ and upperto-lower segment ratio was 1.05 . He had generalized hyperpigmentation, which was more prominent in the palmer creases, knuckles, oral mucosa, extensor surfaces and on pressure areas. He was normotensive for age

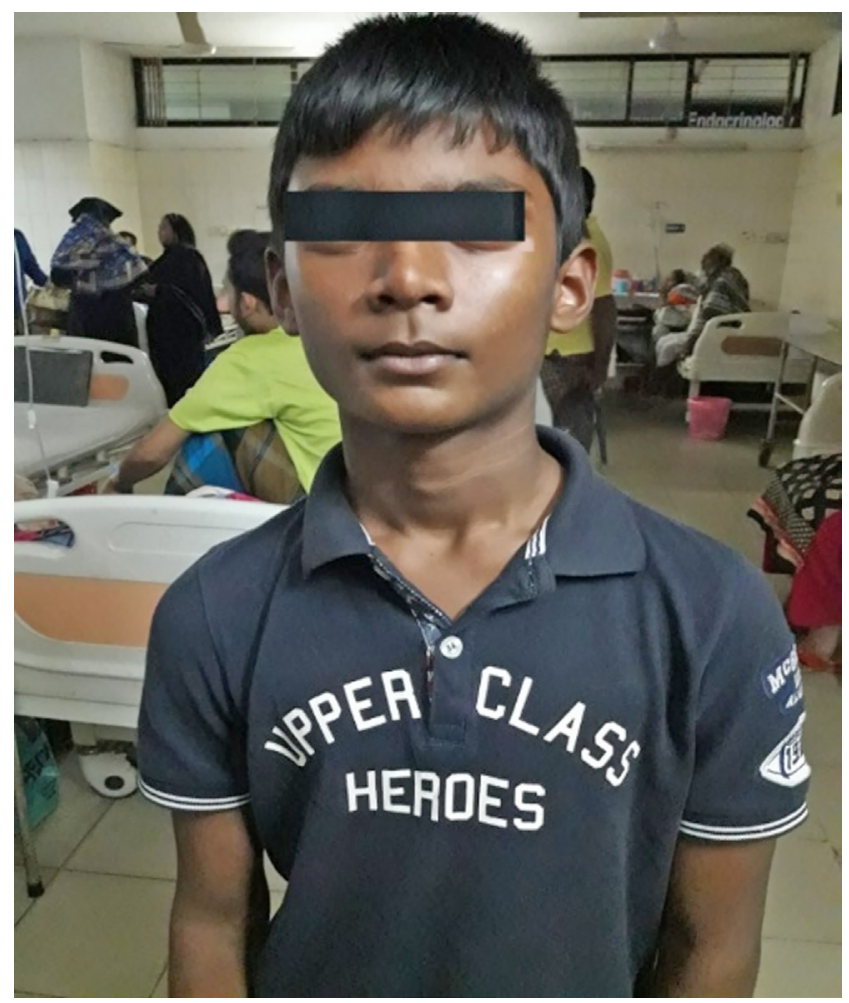

Figure 2

Front profile of the boy. 


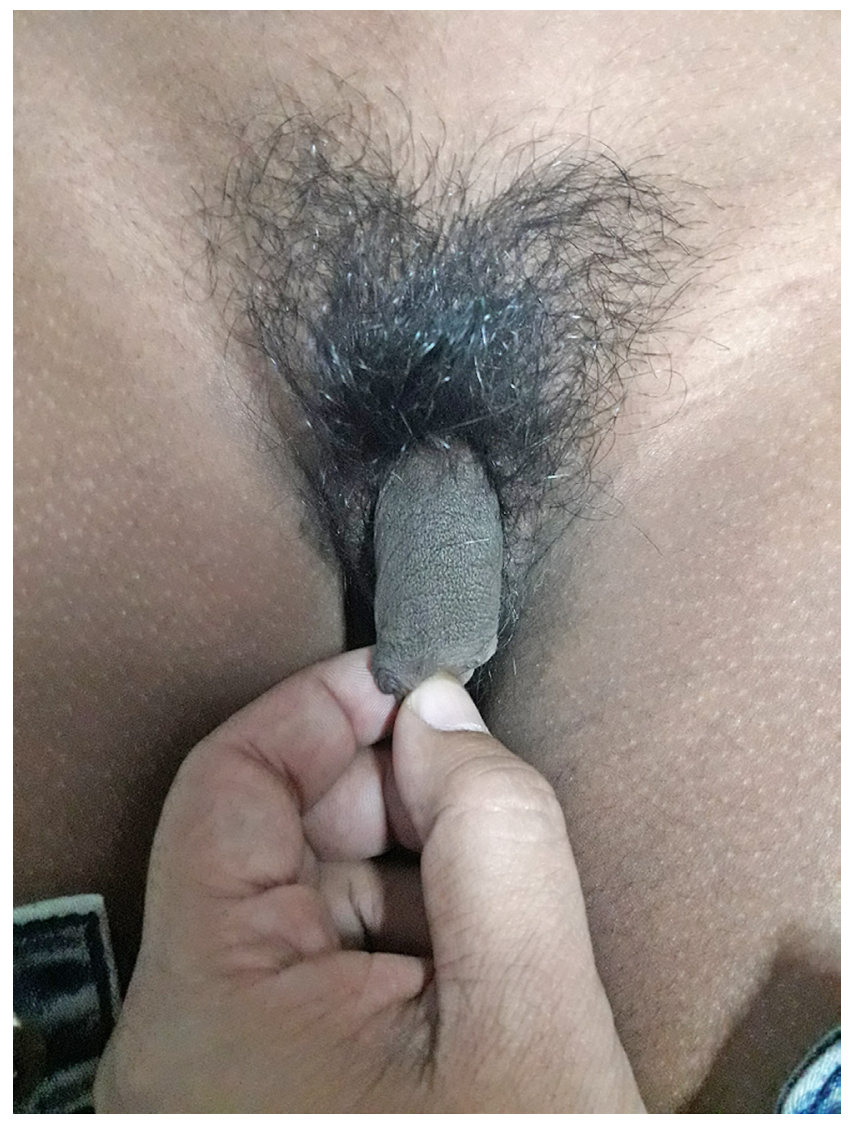

Figure 3

Phallic enlargement.

but with evidence of postural hypotension. Rest of the general and systemic examination including fundoscopy and other vital signs were normal. Sexual maturity rating was consistent with pubic hair-Tanner stage IV, stretched penile length (SPL) of $4 \mathrm{~cm}$ (Fig. 3), and external masculinization score (EMS) was -3 . He had penoscrotal hypospadias, chordae and his scrotal skin was darkened and rugosed but with incomplete fusion and the testes were impalpable within the sac or inguinal region (Fig. 4).

\section{Investigation}

Routine blood tests including liver and renal function, thyroid hormone profile and blood sugar were normal. Radiological bone age was advanced between 16 and 17 years. Serum electrolyte report showed $\mathrm{Na}-134 \mathrm{mmol} / \mathrm{L}$, $\mathrm{K}-5.6 \mathrm{mmol} / \mathrm{L}, \mathrm{Cl}-103 \mathrm{mmol} / \mathrm{L}$. Hormonal assay (Table 1) showed low serum LH and FSH with inappropriately high age-matched testosterone level. Serum basal cortisol was low with elevated adrenocorticotrophic hormone (ACTH), high normal $17-\mathrm{OH}$ progesterone but disproportionately

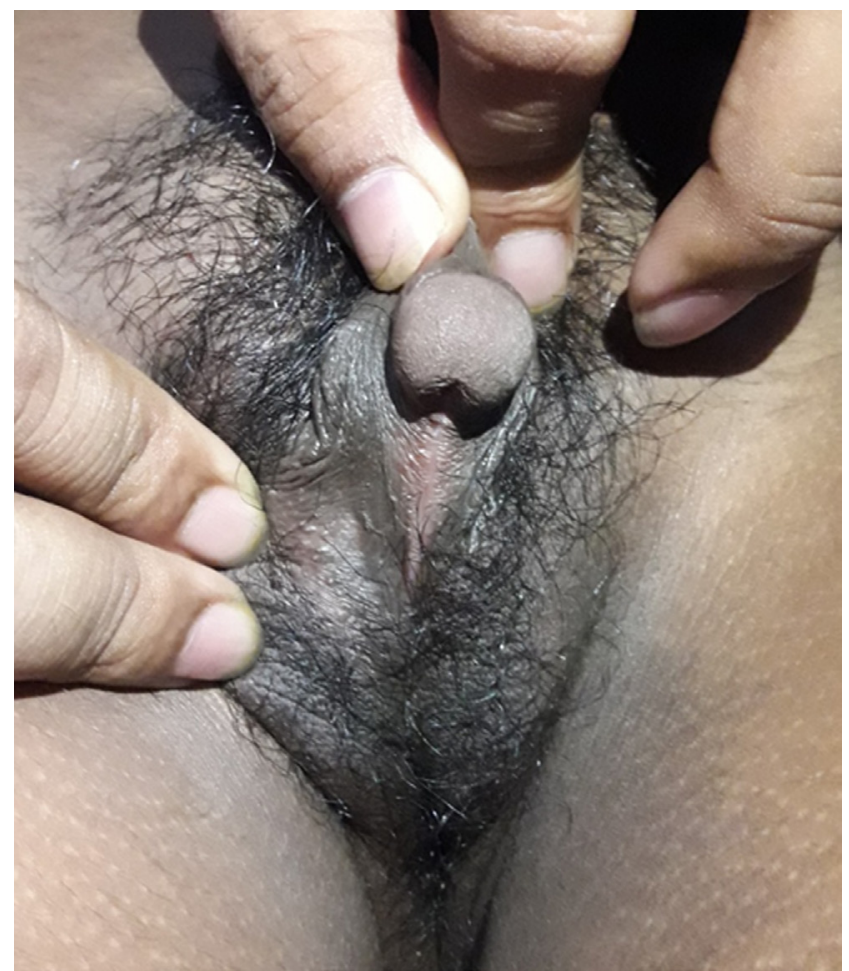

Figure 4

Appearance of external genitalia.

elevated DHEA-S. The presence of genital ambiguity along with the pattern of adrenal hormonal profiles necessitated for the $\Delta 5$ precursor $17-\mathrm{OH}$ pregnenolone and was found to be markedly elevated (Table 1). High baseline ACTH and 17-OH-pregnenolone obviated the need for ACTH stimulation test. CT scan of the abdomen showed a soft tissue density structure, measuring about $15 \times 13 \mathrm{~mm}$ at the right side of the pelvic cavity in the region of inguinal canal likely representing right testis; however, left testis could not be delineated, both the adrenals were mildly enlarged $(25 \times 7.9 \mathrm{~mm}$ on right and $26 \times 6.7 \mathrm{~mm}$ on left side $)$ with uniform post-contrast enhancement (Fig. 5). An HCG stimulation test exhibited an elevated testosterone level from baseline to $561.63 \mathrm{ng} / \mathrm{dL}$, confirming the presence of intra-abdominal viable testis. The presentation led to karyotyping and the report was quite unexpected: mosaic KS 47,XXY/46,XX (3:1). Ultimately, sequencing of HSD3B2 gene was done that showed the two homozygous mis-sense mutations V299I (GTA>ATA), S309T (TCC>ACC) and one heterozygous mutation Q311R (CAA>CGA) (Fig. 6).

\section{Treatment}

We discharged the patient with hydrocortisone $5 \mathrm{mg}$ in the morning and $10 \mathrm{mg}$ at night, fluodrocortisone $0.1 \mathrm{mg}$ 
Table 1 Initial hormonal status of the subject.

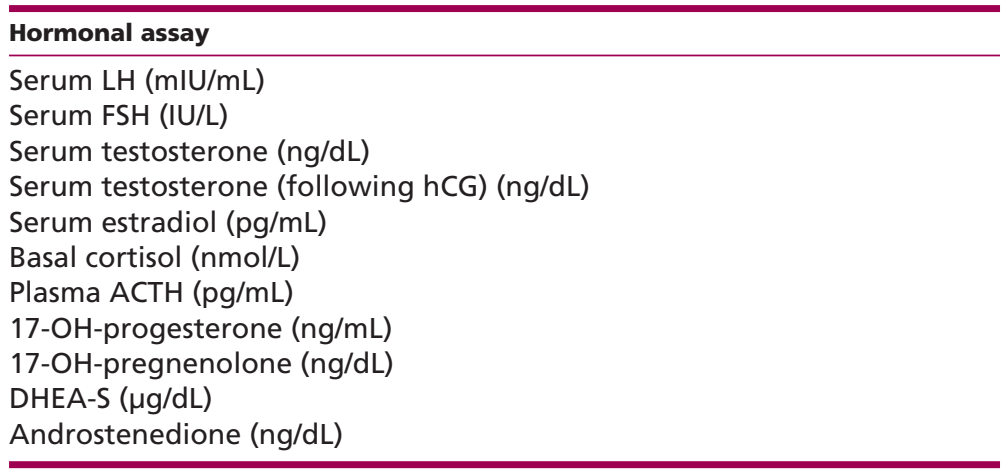

\begin{tabular}{ll}
\hline Test result \\
\hline 0.19 \\
3.83 \\
276 \\
561.63 \\
11.8 \\
129 \\
269 \\
2.15 \\
2097 \\
331.80 \\
34 \\
\hline
\end{tabular}

\begin{tabular}{ll}
\hline Reference value \\
\hline$\leq 0.44$ \\
$<3$ \\
$\leq 42$ \\
$\mathrm{~N} A$ \\
$\leq 4$ \\
$138-690$ \\
$0.00-46$ \\
$0.5-2.1$ \\
$\leq 72$ \\
$<186$ \\
$6-115$
\end{tabular}

daily along with necessary advice. One month later, the urologist performed orchidopexy of right testis, whereas the left testis that found to be rudimentary was sacrificed (Fig. 7). At follow-up after 3 months, he had subjective improvement in terms of remission of fatigue, nausea and diarrhea, his skin became less pigmented though he developed mild tender gynecomastia.

\section{Outcome and follow-up}

At subsequent follow-up at 6 months, the gynecomastia resolved and hormonal profile showed suppression of ACTH and adrenal androgens with biochemical unmasking of hypergonadotropic hypogonadism due to KS (Table 2). At present, correction of hypospadias as well as genetic screening of rest of the family members are awaited. In future, he will probably require androgen replacement when his hypogonadal features become more evident.

\section{Discussion}

$\mathrm{CAH}$ due to $3 \beta$-HSD deficiency is a rare autosomal recessive disorder that results from mutations within the HSD3B2

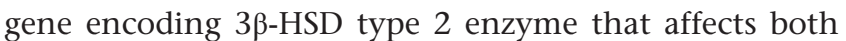
adrenal and gonadal steroid production. The HSD3B2 gene, located on chromosome 1p13.1, is expressed almost exclusively in the adrenals and gonads while the highly homologous $3 \beta$-HSD type 1 (HSD3B1), located in the vicinity of the same chromosome, is expressed in placenta and peripheral tissues, such as skin, breast and prostate (6). The HSD3B2 gene consists of four exons, encodes a protein of 371 amino acids and shares $93.5 \%$ homology with type 1 . In proximity residue, there are 5 pseudogenes (HSD3B $\psi 1-5)$; two of these pseudogenes ( $\psi 1$ and $\psi 2$ ) separate the two expressed HSD3B1 and HSD3B2 genes, preventing them from sharing common promoter elements. Thus, along with the tissue-specific differential expression, HSD3B1 is usually normal in patients with
3ß-HSD2 deficiency (6). A strong genotype-phenotype correlation exists. Nonsense and frame-shift mutations that ablate enzyme transcription or function result in salt-wasting forms of $3 \beta-H S D 2$ deficiency. Conversely, single amino-acid substitutions that moderately decrease the affinity of the enzyme for substrate or cofactors,

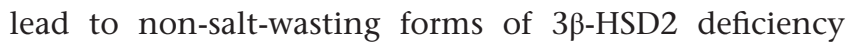
$(7,8,9)$. The enzyme HSD3 32 catalyzes the 3-betadehydrogenation and isomerization of the double bond of the steroid B ring to the steroid A ring, converting

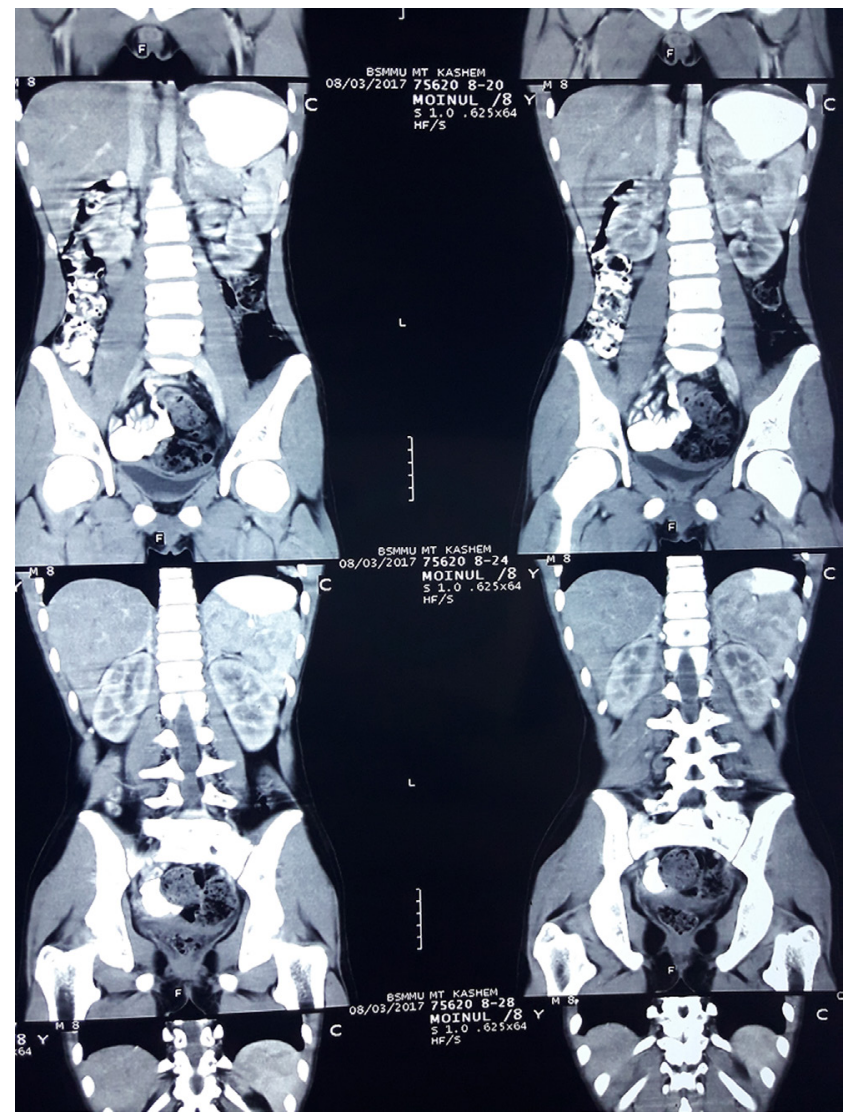

Figure 5

CT scan of adrenal glands. 
A
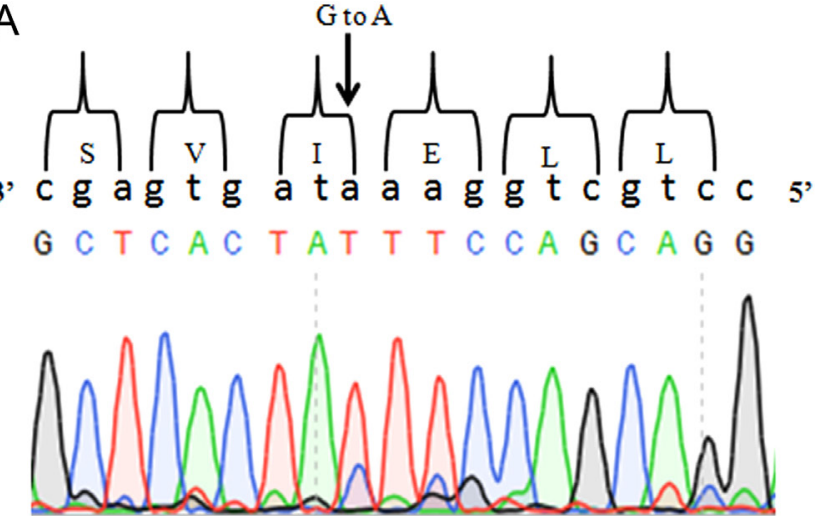

B

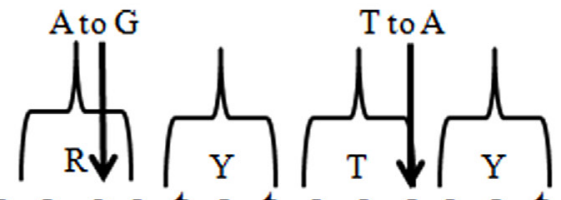

3'

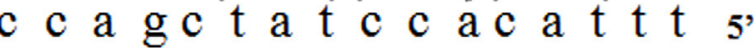

$G G T C G A T A G G T G T A A A$

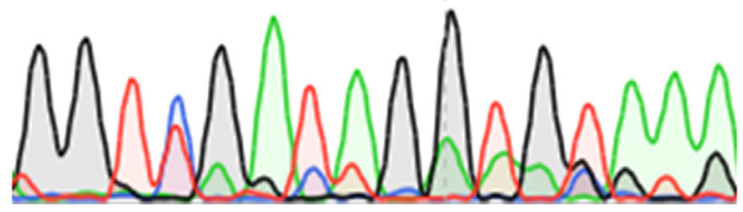

Figure 6

Partial nucleotide sequences of HSD3B2 gene showing in black arrows the homozygous $\mathrm{G}>\mathrm{A}$ transversion ( $\mathrm{A}$ ) and heterozygous $\mathrm{A}>\mathrm{G}$ transversion and $T>A$ transition (B) in antisense strands. Upper panels in small letters show the complimentary sequences of the nucleotides and the three letter blocks show the respective amino acids.

$\Delta 5$ to $\Delta 4$ steroids such as pregnenolone to progesterone (mineralocorticoid pathway), 17- $\alpha$-hydroxypregnenolone to 17- $\alpha$-hydroxyprogesterone (glucocorticoid pathway), DHEA to androstenedione and androstenediol to testosterone (sex-steroid pathway). Therefore, absence of this enzyme impairs all these $\Delta 4$ steroid production while low levels of cortisol resulting in increased ACTH stimulation of steroids prior to the $3 \beta$-HSD step, producing increased accumulation and secretion of $\Delta 53 \beta$ hydroxy steroids: pregnenolone, 17- $\alpha$-hydroxypregnenolone and DHEA. Adrenal insufficiency occurs secondary to aldosterone and cortisol deficiency. 46,XY individuals with severe defects may present with ambiguous genitalia, hypospadias, severe adrenal insufficiency in infancy, poor virilization at puberty and gynecomastia, whereas milder forms with penoscrotal hypospadias and premature adrenarche. Indeed, this differentiation is not

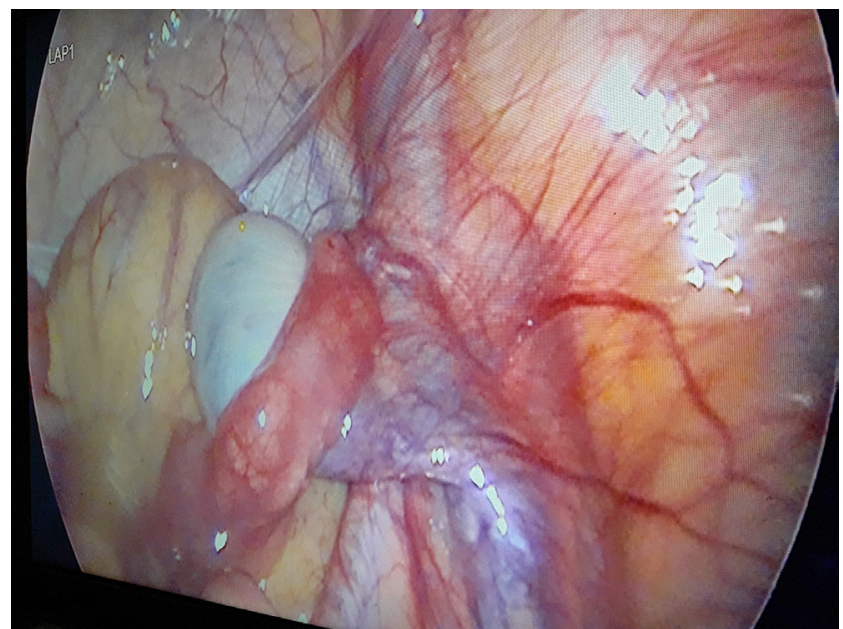

Figure 7

Intra-abdominal testis on right side.

straightforward and impaired male sexual differentiation correlates poorly with salt-wasting forms; moreover, identical mutations have also been found in both the forms (10). Virilization or spontaneous puberty has been reported in patients secondary to either direct effects of DHEA or to sufficient conversion of DHEA to testosterone via peripheral type I $3 \beta$-HSD isoenzyme (10).

On the other hand, Klinefelter syndrome (KS) is the most common sex chromosome disorder in male characterized by hypergonadotropic hypogonadism, androgen deficiency and impaired spermatogenesis (11). In 1942, Klinefelter et al. published a report on nine men who had enlarged breasts, sparse facial and body hair, small testes and an inability to produce sperm. In 1959, these men with KS were discovered to have an extra X chromosome (genotype XXY) instead of the usual male sex complement (genotype XY) (4). In $80-90 \%$ of the cases this defining karyotype $(47, \mathrm{XXY})$ is universally observed among the patient's cells, whereas various grades of mosaicism $(47, \mathrm{XXY} / 46, \mathrm{XY})$ or a structurally abnormal $\mathrm{X}$ chromosome (e.g. $\mathrm{X}$ isochromosome) may be detected in the remaining cases (12). Individuals with mosaic KS in

Table 2 Hormonal profile following 6 months of suppressive glucocorticoid therapy.

\begin{tabular}{lrrrr}
\hline Hormonal assay & & After treatment & & Before treatment \\
\cline { 1 - 1 } Serum LH (mIU/mL) & & 3.05 & 0.19 \\
Serum FSH (IU/L) & & 13.96 & 3.83 \\
Serum testosterone & & 107.50 & 276 \\
$\quad(\mathrm{ng} / \mathrm{dL})$ & & \\
Plasma ACTH $(\mathrm{pg} / \mathrm{mL})$ & & 7.19 & 269 \\
DHEA-S $(\mu \mathrm{g} / \mathrm{dL})$ & 26.70 & 331.80 \\
\hline
\end{tabular}


particular tend to present milder forms of the syndrome, both with respect to testosterone deficiency and sperm production (13). Mosaicism (mainly 46,XY/47,XXY) commonly arises from either non-disjunction in an early mitotic division of the developing 46, XY zygote or from loss of one of the X chromosome of a 47,XXY conception due to anaphase lagging (14). Phenotypic heterogeneity is a significant feature of KS, while its manifestations can be attributed either to the aneuploidy and the impact of increased gene dosage by the supernumerary $\mathrm{X}$ or the presence of hypogonadism per se (15). Though premature failure of Leydig cell function is observed in KS subjects, hypogonadism is usually not evident before early adulthood (16). In line with this, congenital anomalies of the genital organs driven by hypogonadism such as micropenis, bifid scrotum or hypospadias, although more frequent in KS than in the general population, have an overall low prevalence (17). Accordingly, the temporary surge in gonadotropins observed in early infancy, also known as 'minipuberty', is usually present with FSH levels peaking at 2-3 months of age, followed by a subsequent rapid decline (18). Ultimately, the clinical presentation is highly variable and is modified according to the age of the individual. During infancy, males with KS may have chromosomal evaluations done for hypospadias, small phallus or cryptorchidism (19). The toddlers may present with developmental delay, especially with expressive language skills. The school-aged child may present with language delay, learning disabilities or behavioral/social problems (20). The older child or adolescent may be discovered during an endocrine evaluation for delayed or incomplete pubertal development with eunuchoid body habitus, gynecomastia and small testes (21). Adults are often evaluated for infertility or breast malignancy (22).

The simultaneous occurrence of $\mathrm{CAH}$ and Klinefelter syndrome is extremely rare. The interest in describing this case report lies in the exceptionality of the concurrent occurrence of CAH because of 3 3 -HSD deficiency and mosaic KS 47,XXY/46,XX (3:1). This provides clinical evidence of the coexistence of 2 diseases, the first of which causes androgen excess and the second androgen deficiency.

The index patient as we report after taking informed consent from the legal guardian for publications of clinical details and images was the first issue of a consanguineous marriage. At birth, he presented with ambiguous genitalia, cryptorchidism and micro phallus with penoscrotal hypospadius. At the age of 7 years, he presented with accelerated growth, advanced bone age with phallic enlargement and other features of precocious puberty along with high testosterone levels except for his cryptorchidism that remained unexplained. So we were dealing with a patient who presented with disordered sexual differentiation (DSD) evident at birth and later on developed evidence of precocious puberty. Though there was no history of classic salt wasting crisis yet he complained of nausea, occasional diarrhea and progressive blackening of skin. These features could be explained by cortisol deficiency and ACTH excess indicating one of the varieties of $\mathrm{CAH}$ that at the same time leads to in utero and early life androgen deficiency causing ambiguous genitalia in a phenotypic male. There are certain varieties of $46 \mathrm{XY}$ DSD that may lead to pubertal virilization and growth acceleration like some variants of $\mathrm{CAH}$ e.g. deficiency of $3 \beta$-HSD 2, 17 $\beta$-HSD-3 or other non-adrenal disorders like partial androgen insensitivity syndrome (PAIS), $5 \alpha$-reductase- 2 deficiency or ovo-testicular DSD. CAH in our patient was proven biochemically by high ACTH and low cortisol, thereby excluding non-adrenal disorders from our list. On the other hand, 17 $\beta$-HSD-3 deficiency usually presents with female phenotype at birth. As this enzyme is required in conversion of androstenedione to testosterone without affecting glucocorticoid or mineralocorticoid pathway so it was unlikely in this case. This patient had high $17 \mathrm{OH}$-pregnenolone and low $17 \mathrm{OH}$ progesterone level indicating deficiency of $3 \beta$-HSD. $\mathrm{He}$ had gonadotropin-independent precocious puberty as evidenced by low LH, FSH with high DHEA-S and testosterone. It can be explained by $\mathrm{CAH}$ due to $3 \beta-\mathrm{HSD}$ deficiency where features of excess androgen found either by direct effects of high DHEA or to sufficient conversion of DHEA to testosterone via peripheral type I 3 $\beta$-HSD isoenzyme. However, presence of cryptorchidism and hypospadias pointed toward androgen insufficiency that was attributable to mosaic variety of $\mathrm{KS} 47, \mathrm{XXY} / 46, \mathrm{XX}$ (3:1) (19). Whereas the precocity of puberty was a feature of androgen excess that went against the features of KS. This excess androgen also masked some other hypoandrogenic features of KS. Probably peripheral conversion of adrenal androgen into testosterone and estrogen was sufficient enough to prevent the development of eunuchoidism as expected in KS. So, we can speculate that high adrenal androgen secretion by $\mathrm{CAH}$ had a greater relevance than the low testicular androgen production, typical of KS. Till now there are 5 reported cases of co-occurrence of KS with CAH, one of them had 3BHSD2 deficiency but with a different presentation and the rest of them had $21-\mathrm{OH}$ deficiency $(23,24,25,26,27)$. Four of them were detected in boys and another one in a 51-year-old male. The first four cases were diagnosed with $\mathrm{CAH}$ in early 
infancy or childhood and were started on glucocorticoid treatment. However, they had small testicular volume and pubertal delay raising the suspicion of hypogonadism. So, karyotyping was done subsequently revealing KS. Balestrieri et al. reported occurrence of KS and 21OHD $\mathrm{CAH}$ a 51-year-old man who came to their attention because of mastodynia; he had bilateral gynecomastia with normal virilization and muscular masses, but both testes were small $(4 \mathrm{~mL})$ with a firm consistency. Later on his karyotyping and hormonal profile revealed co-existence of 21OHD CAH with KS (27). Probably our patient is the first reported case of $3 \beta$-HSD deficiency $\mathrm{CAH}$ with mosaic KS that was detected simultaneously rather than on later follow-up, unlike the other cases. The clue to this suspicion was bilateral cryptorchidism that was implausible to result from $\mathrm{CAH}$ and pointed towards co-existent hypogonadism. Though peripheral sexual precocity, instead of hypogonadism was apparent biochemically, possibly because of his prepubertal age of presentation and due to excess adrenal androgen, yet, karyotype revealed a mosaic KS.

Most patients with $3 \beta$-HSD deficiency require treatment with mineralocorticoid, glucocorticoid and androgen replacement. We started him on mineralocorticoid and glucocorticoid replacement and orchiopexy was performed. At present, he is on regular follow-up and waiting for corrective surgery for hypospadias. Following initiation of treatment he developed gynecomastia that might be due to suppression of adrenal androgen production after treatment with corticosteroid unmasking his hypogonadism. However, in subsequent follow-up, it resolved and hormonal profile showed evidence of hypergonadotropic hypogonadism (Table 2), unveiling the biochemical picture of KS.

The HSD $3 B 2$ gene provides instruction for making $3 \beta$-HSD type 2 enzyme. Various mutations in the HSD3B2 gene have been shown to be responsible for the varying phenotypic presentations. Missense mutations in the type II gene have been described in non-classic late-onset $3 \beta$ HSD deficiency (6). Genetic analysis of HSD3B2 gene was performed, where RNA was extracted from peripheral blood sample and reverse-transcribed to synthesize cDNA. cDNA of HSD3B2 genes were amplified using PCR with specific primer. PCR products were then purified and analyzed by capillary electrophoresis based on Sanger sequencing protocol (28). The DNA sequencing of the patient's HSD3B2 gene revealed the two homozygous missense mutations V299I (GTA>ATA), S309T (TCC>ACC) and one heterozygous mutation Q311R (CAA>CGA) (Fig. 6).

\section{Conclusion}

The unique presentation of our subject affected by both CAH due to 3 $\beta$-HSD deficiency and mosaic Klinefelter's syndrome $(47, \mathrm{XXY} / 46, \mathrm{XX})$ suggests that these two syndromes, the first inducing high levels and the second accounting for low levels of circulating androgens, balanced out in determining the patient's phenotype.

\section{Declaration of interest}

The authors declare that there is no conflict of interest that could be perceived as prejudicing the impartiality of the research reported.

\section{Funding}

Fund was provided by the investigators themselves. Genetic study was performed at a nominal cost by the investigators of Dhaka University.

\section{Patient consent}

Written informed consent was obtained from the legal guardian of the patient for publication of the submitted article and the accompanying images.

\section{Author's contribution statement}

The clinical and biochemical part of the research was carried out by the investigators of BSMMU, Dhaka and the genetic analysis and its subsequent description by the investigators of Dhaka University. All the authors read and approved the draft.

\section{References}

1 Merke DP. Approach to the adult with congenital adrenal hyperplasia due to 21-hydroxylase deficiency. Journal of Clinical Endocrinology and Metabolism 200893 653-660. (https://doi.org/10.1210/jc.2007-2417)

2 Pang S. Congenital adrenal hyperplasia owing to 3 betahydroxysteroid dehydrogenase deficiency. Endocrinology Metabolism Clinics of North America 200130 81-99, vi-vii. Review. (https://doi. org/10.1016/S0889-8529(08)70020-3)

3 Lanfranco F, Kamischke A, Zitzmann M \& Nieschlag E. Klinefelter's syndrome. Lancet 2004364 273-283. (https://doi.org/10.1016/ S0140-6736(04)16678-6)

4 Klinefelter HF, Reifestein EC \& Albright F. Syndrome characterized by gynecomastia, aspermatogenesis without a Leydigism and increased excretion of follicle-stimulating hormone. Journal of Clinical Endocrinology and Metabolism 19422 615-627. (https://doi. org/10.1210/jcem-2-11-615)

5 Velissariou V, Christopoulou S, Karadimas C, Pihos I, KanakaGantenbein C, Kapranos N, Kallipolitis G \& Hatzaki A. Rare XXY/ $\mathrm{XX}$ mosaicism in a phenotypic male with Klinefelter syndrome: case report. European Journal of Medical Genetics 200649 331-337. (https://doi.org/10.1016/j.ejmg.2005.09.001)

6 Simard J, Ricketts ML, Gingras S, Soucy P, Feltus FA \& Melner MH. Molecular biology of the 3beta-hydroxysteroid dehydrogenase/ delta5-delta4 isomerase gene family. Endocrine Reviews 200526 525-582. (https://doi.org/10.1210/er.2002-0050) 
7 Zhang L, Mason JI, Naiki Y, Copeland KC, Castro-Magana M, Gordon-Walker TT, Chang YT \& Pang S. Characterization of two novel homozygous missense mutations involving codon 6 and 259

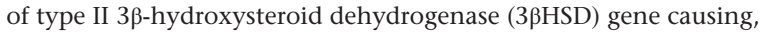
respectively, nonsalt-wasting and salt-wasting 33HSD deficiency disorder. Journal of Clinical Endocrinology and Metabolism 200085 1678-1685. (https://doi.org/10.1210/jcem.85.4.6539)

8 Rheaume E, Sanchez R, Simard J, Chang YT, Wang J, Pang S \& Labrie F. Molecular basis of congenital adrenal hyperplasia in two siblings with classical nonsalt-losing 3 $\beta$-hydroxysteroid dehydrogenase deficiency. Journal of Clinical Endocrinology and Metabolism 199479 1012-1018. (https://doi.org/10.1210/jcem.79.4.7962268)

9 Russell AJ, Wallace AM, Forest MG, Donaldson MD, Edwards CR \& Sutcliffe RG. Mutation in the human gene for 3 3 -hydroxysteroid dehydrogenase type II leading to male pseudohermaphroditism without salt loss. Journal of Molecular Endocrinology 199412 225-237. (https://doi.org/10.1677/jme.0.0120225)

10 Achermann JC \& Hughes IA. Pediatric disorders of sex development. In Williams Textbook of Endocrinology, pp 893-963. Eds S Melmed, KS Polonsky, PR Larsen \& HM Kronenberg. Philadelphia, PA: Elsevier, 2016.

11 Smith CM \& Bremner WJ. Klinefelter syndrome. Archive of Internal Medicine 1998158 1309-1314. (https://doi.org/10.1001/ archinte.158.12.1309)

12 Kanakis GA \& Nieschlag E. Klinefelter syndrome: more than hypogonadism, Metabolism Clinical and Experimental $2018 \mathbf{8 6}$ 135-144. (https://doi.org/10.1016/j.metabol.2017.09.017)

13 Samplaski MK, Lo KC, Grober ED, Millar A, Dimitromanolakis A \& Jarvi KA. Phenotypic differences in mosaic Klinefelter patients as compared with non-mosaic Klinefelter patients. Fertility and Sterility 2014101 950-955. (https://doi.org/10.1016/j.fertnstert.2013.12.051)

14 Bonomi M, Rochira V, Pasquali D, Balercia G, Jannini EA \& Ferlin A. Klinefelter syndrome (KS): genetics, clinical phenotype and hypogonadism. Journal of Endocrinological Investigation $2017 \mathbf{4 0}$ 123-134. (https://doi.org/10.1007/s40618-016-0541-6)

15 Arnold AP, Reue K, Eghbali M, Vilain E, Chen X, Ghahramani N, Itoh Y, Li J, Link JC, Ngun T, et al. The importance of having two $\mathrm{X}$ chromosomes. Philosophical Transactions of the Royal Society of London: Series B, Biological Sciences 2016371 20150113. (https://doi. org/10.1098/rstb.2015.0113)

16 Bojesen A, Groth K, Høst C \& Skakkeb'k A. The role of hypogonadism in Klinefelter syndrome. Asian Journal of Andrology 201416 185. (https://doi.org/10.4103/1008-682X.122201)

17 Lee YS, Cheng AWF, Ahmed SF, Shaw NJ \& Hughes IA. Genital anomalies in Klinefelter's syndrome. Hormone Research in Paediatrics 200768 150-155. (https://doi.org/10.1159/000106375)

18 Cabrol S, Ross JL, Fennoy I, Bouvattier C, Roger M \& Lahlou N. Assessment of Leydig and Sertoli cell functions in infants with nonmosaic Klinefelter syndrome: insulin-like peptide 3 levels are normal and positively correlated with LH levels. Journal of Clinical Endocrinology and Metabolism 201196 E746-E743. (https://doi. org/10.1210/jc.2010-2103)

19 Caldwell PD \& Smith DW. The XXY (Klinefelter's) syndrome in childhood: detection and treatment. Journal of Pediatrics 197280 250-258. (https://doi.org/10.1016/S0022-3476(72)80586-9)

20 Walzer S, Wolff PH, Bowen D, Silbert AR, Bashir AS, Gerald PS $\&$ Richmond JB. A method for longitudinal study of behavioral development in infants and children: the early development of XXY children. Journal of Child Psychology and Psychiatry 197819 213-229. (https://doi.org/10.1111/j.1469-7610.1978.tb00465.x)

21 Robinson A, Bender B \& Linden MG. Summary of clinical findings in children and young adults with sex chromosome anomalies. In Children and Young Adults with Sex Chromosome Aneuploidy Birth Defects: Original Article Series, Vol. 26, pp 225-228. Eds JA Evans \& JL Hamerton. New York: Wiley-Liss, for the March of Dimes Birth Defect Foundation, 1991.

22 Okada H, Fujioka H, Tatsumi N, Kanzaki M, Okuda Y, Fujisawa M, Hazama M, Matsumoto O, Gohji K, Arakawa S, et al. Klinefelter's syndrome in the male infertility clinic. Human Reproduction 199914 946-952. (https://doi.org/10.1093/humrep/14.4.946)

23 Gortakowski M, Conroy R, Aguiar L \& Allen H. Premature pubarche in a child with abnormal $3 \beta$-hydroxysteroid dehydrogenase function and Klinefelter syndrome: the intriguing relationship between androgen deficiency and excess. Clinical Case Reports. 20175 57-60. (https://doi.org/10.1002/ccr3.742)

24 Yamaguchi T, Abe H, Kuwano T, Sugimoto T \& Chihara K. Congenital adrenal hyperplasia with 47, XXY Klinefelter syndrome. Experimental and Clinical Endocrinology 1994102 348-350. (https:// doi.org/10.1055/s-0029-1211302)

25 Parker EA, Hovanes K, Germak J, Porter F \& Merke DP. Maternal 21 hydroxylase deficiency and uniparentalisodisomy of chromosome 6 and $\mathrm{X}$ results in a child with 21-hydroxylase deficiency and Klinefelter syndrome. American Journal of Medical Genetics Part A 2006 140A 2236-2240. (https://doi.org/10.1002/ajmg.a.31408)

26 Zanella G, Tornese G, Mascheroni E, Faleschini E, Ventura A \& Barbi E. A Klinefelter boy with congenital adrenal hyperplasia: too much or too little androgens? Italian Journal of Pediatrics $2018 \mathbf{4 4} 43$. (https://doi.org/10.1186/s13052-018-0485-x)

27 Balestrieri A, Zirilli L, Madeo B, Pignatti E, Rossi G, Carani C \& Rochira V. 21Hydroxylase deficiency and case report Klinefelter syndrome in an adult man: striking a balance between androgen excess and insufficiency. Journal of Andrology 200829 605-609. (https://doi.org/10.2164/jandrol.107.004648)

28 Sanger F \& Coulson AR. A rapid method for determining sequences in DNA by primed synthesis with DNA polymerase. Journal of Molecular Biology 197594 441-448. (https://doi.org/10.1016/00222836(75)90213-2)

Received in final form 5 September 2018 Accepted 19 September 2018 